Journal of Information Technology and Digital World (2020)

Vol.02/ No. 02

Pages: 116-122

https://www.irojournals.com/itdw/

DOI: https://doi.org/10.36548/jitdw.2020.2.005

\title{
A Hybrid-Algorithm for E-project Selection on Social Media
}

\author{
Dr. A. Pasumponpandian, \\ Professor, \\ Computer Science Engineering, \\ KGiSL Institute of Technology, \\ Coimbatore, India. \\ Email id:pasumponpandian32@gmail.com
}

\begin{abstract}
The integration of two of the biggest giants in the computing world has resulted in the development and advancement of new methodologies in data processing. Cognitive computing and big data analytics are integrated to give rise to advanced technologically sound algorithms like MOIWO and NSGA. There is an important role played by the E-projects portfolio selection (EPPS) issue in the web development environment that is handled with the help of a decision making algorithm based on big data. The EPPS problem tackles choosing the right projects for investment on the social media in order to achieve maximum return at minimal risk conditions. In order to address this issue and further optimize EPPS probe on social media, the proposed work focuses on building a hybrid algorithm known as NSGA-II-MOIWO. This algorithms makes use of the positive aspects of MOIWO algorithm and NSGA-II algorithm in order to develop an efficient one. The experimental results are recorded and analyzed in order to determine the most optimal algorithm based on the return and risk of investment. Based on the results, it is found that NSGA-II-MOIWO outperforms both MOIWO and NSGA, proving to be a better hybrid alternative.
\end{abstract}

Keywords: Fuzzy Logic, MOIWO, NSGA-II, Big Data, E-project portfolio selection problem

\section{Introduction}

In the recent years, web development projects have been gaining much attention from various researchers from around the world. Among these projects the concept of E-portfolio is a fresh concept that targets social media investors towards discovering the best portfolio to suit their need. Chantanarungpak in [1] first introduced E-portfolio to the work which collects many portfolio from many formats and stores this information using computing [7]. This is possible by interlinking the concepts of web development and financial portfolio. Similarly, another advancement in this area is the E-project portfolio selection problem (EPPS) which focuses on finding the projects that have low investment risk and high return, which was introduced by Markowitz [2]. The biggest issue faced by many developing countries such as India is the absence of appropriate investment platforms for organizations and individuals. Moreover, active participation by the people plays a key role in the Eprojects for web development companies [3-4]. The biggest worry in E-project based company rests in the formation of optimal EPPS and selection of the right investment bonds for an effective outcome. It is possible for people working on it ending up collecting large quantities of data for projects that are futile and unused which will make the process of selection very tedious when compared to other 
Journal of Information Technology and Digital World (2020)

Vol.02/ No. 02

Pages: $116-122$

https://www.irojournals.com/itdw/

DOI: https://doi.org/10.36548/jitdw.2020.2.005

conventional approaches [5]. This can be overcome by proposing a methodology to process vast quantities of data in an efficient manner, resulting in the manifestation of critical E-project components which will give the client a better investment decision [6].

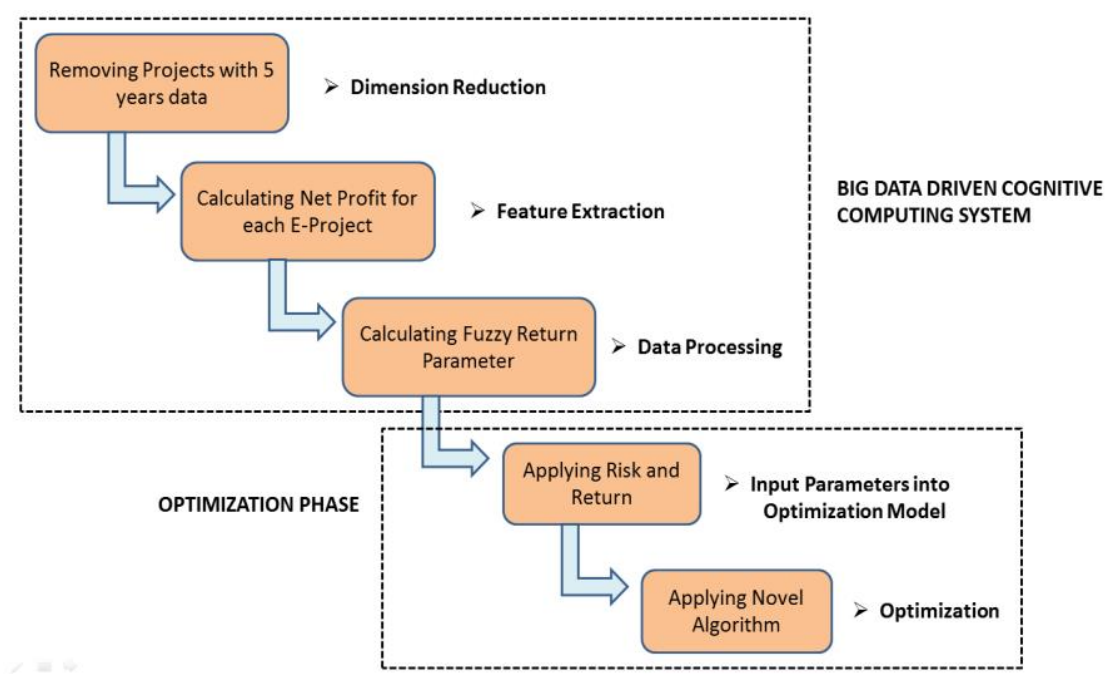

Fig.1. Steps Involved in Cognitive Computing

The many features of cognitive computing and big data analytics are used for better perception of information security, trust and privacy issues. The major contributions and objectives of this paper are as follows:

- To provide a solution to the EPPS based on big data driven computing and social media, a mathematical model is proposed. This will also include minimizing the risk faced in terms of kurtosis measures, skewness and variance and will also increase the expected returns.

- A new algorithm known as NSGA-III MOIWO, which is a hybrid is proposed in this paper. It takes the positive aspects of Multi-Object Invasive Weed Optimization (MOIWA) and NonDominated Sorting Genetic Algorithm III (NSGA-III) and integrates it to form this new algorithm in order to deal with problems which are highly complex.

- In order to handle uncertainty in data, fuzzy mechanism is used in NSGA-III MOIWO.

- The performance of the algorithm proposed is evaluated by means of extensive simulation and about 124 active projects have been viewed over the past 3 years to gather the data.

\section{Data Conversion to Fuzzy Parameter}

In order to verify the performance of the proposed NSGA-II -MOIWO methodology, a total of $250 \mathrm{E}-$ projects [8] have been gathered from various resources over the period of 4 years since 2016. The data set derived has been used as the raw data based upon the collected during these years. In order to make use of this data, it is essential to convert this data into fuzzy return parameters which can be used for 
Journal of Information Technology and Digital World (2020)

Vol.02/ No. 02

Pages: $116-122$

https://www.irojournals.com/itdw/

DOI: https://doi.org/10.36548/jitdw.2020.2.005

further processing, In this proposed work, we have established the conversion of data into fuzzy return parameters by means of evaluating the minimum, maximum and average of the profit since 2016. The lower bound for every project is equivalent to the minimum profit and the maximum profit in 2019 is found to be equivalent to the upper bound [9-11]. Also, the average return is equivalent to the middle bound data. Based on this calculation, it is now possible to reduce the dimension of the E-projects and make it compatible for feature extraction. This is essential as the net profit of the project is calculated by feature extraction procedure in this paper in order to determine the net profit [12]. Hence the input parameters of the proposed system include risk of investment along with fuzzy return.

\section{Parameter Setting}

MATLAB software is used to evaluate the proposed methodology in the form of a code. The risk of project portfolio, efficiency and objective function along with total run time of the computation process are observed at every iteration. The following list gives an overview of the different parameters set:

- Upper Bound and Lower Bound for Decision Variables: When an E-project involves a constraint, the maximum and minimum ratio of investment that the project can handle is to be included as part of the problem. The proposed work uses 0.1 and 0.001 as the maximum and minimum ratio of investment for the E-projects selected.

- Risk-averse coefficient: The efficiency of the boundary is traced by determining the risk factor to be used. The value of risk factor will lie between 0 and 1 . To aid this, a risk-aversion coefficient is set such that it uses 0.1 unit as step size to vary while mapping it with the boundary efficiency. Using this size, it is possible to achieve a boundary efficiency of 10 points, paving way to compare the points in an accurate manner.

- $\mathrm{K}$ : This represent the size of the project portfolio. It represents the total number of E-projects that are to be chosen for investment purpose. The value of $\mathrm{K}$ is set at $3,5,10,15,25$ and 50.

\section{Algorithm Implementation}

NSGA-III and NSGA-III MOIWO have been executed for different coefficients of risk aversion and sizes of projects. For the purpose of demonstration, the E-project's efficient boundaries are observed and the following experimentation is carried out.

\section{- When $K=10$}

At the initial step, the E-project portfolio size is fixed at 10 and based on the varying values of risk aversion coefficient, the risk as well as the return of investment is computed. At the same time, we can also calculate the objective function. Finally the combination of returns and risk in the linear form are 
Journal of Information Technology and Digital World (2020)

Vol.02/ No. 02

Pages: $116-122$

https://www.irojournals.com/itdw/

DOI: https://doi.org/10.36548/jitdw.2020.2.005

determined. Based on the experimental observation, it is found that as the risk aversion coefficient increases, there will be a parallel decrease in the investment risk portfolio. This is mainly because, the effect of return will decrease and that of variance will increase as the risk aversion coefficient begins to increase. This is where NSGA-III algorithm will play a crucial role in solving this issue. One should take into consideration that this algorithm doesn't require the conversion of return and risk to goal since it is possible to optimize both the parameters with multi-objective structure.

\section{- When $K=50$}

A similar procedure was carried out for E-projects of the size 50. Based on the observations made by the NSGA III MOIWO algorithm, it is found that there is a decrease in return of investment as the risk aversion increases. This shows that when there is an increase in risk aversion the major focus of the issue is to be cautious with maximizing returns and to decrease the risk. This will lead to decreasing the lower objective function value.

\section{Results and Discussion}

The linear risk-return combination with varying risk aversion coefficient is examined for understanding the performance of the algorithms in an effective manner. Fig. 2 represents the graph of the return and risk investment for varying risk aversion values for $\mathrm{K}=10$. Based on examination, it can be seen that the weighted risk and return measure results for the varying values of risk aversion coefficient are characterized by the two algorithms in which they operate namely NSGA-III algorithm and MOIWO algorithm. The output indicates the for objective function of NSGA-III is higher than that of MOIWO for almost every instant of the risk-aversion coefficient except at 0.85 . Hence it is declared that the hybrid of the two algorithms excels both the basic individual algorithms.

Similarly in Fig.4, for $\mathrm{k}=10$, it is observed that for the varying risk aversion coefficient value, there is subsequent variation in objective function. It can be seen from the graph that there is much difference between the performance of NSGA-II and MOIWO. It is worth noting that for MOIWO examples, there are very low values of NSGA-II and the difference between the two increases further. It indicates that when the problem's dimension increases, the MOIWO effectiveness will also subsequently begin to increase when compared to other algorithms. 
Journal of Information Technology and Digital World (2020)

Vol.02/ No. 02

Pages: $116-122$

https://www.irojournals.com/itdw/

DOI: https://doi.org/10.36548/jitdw.2020.2.005

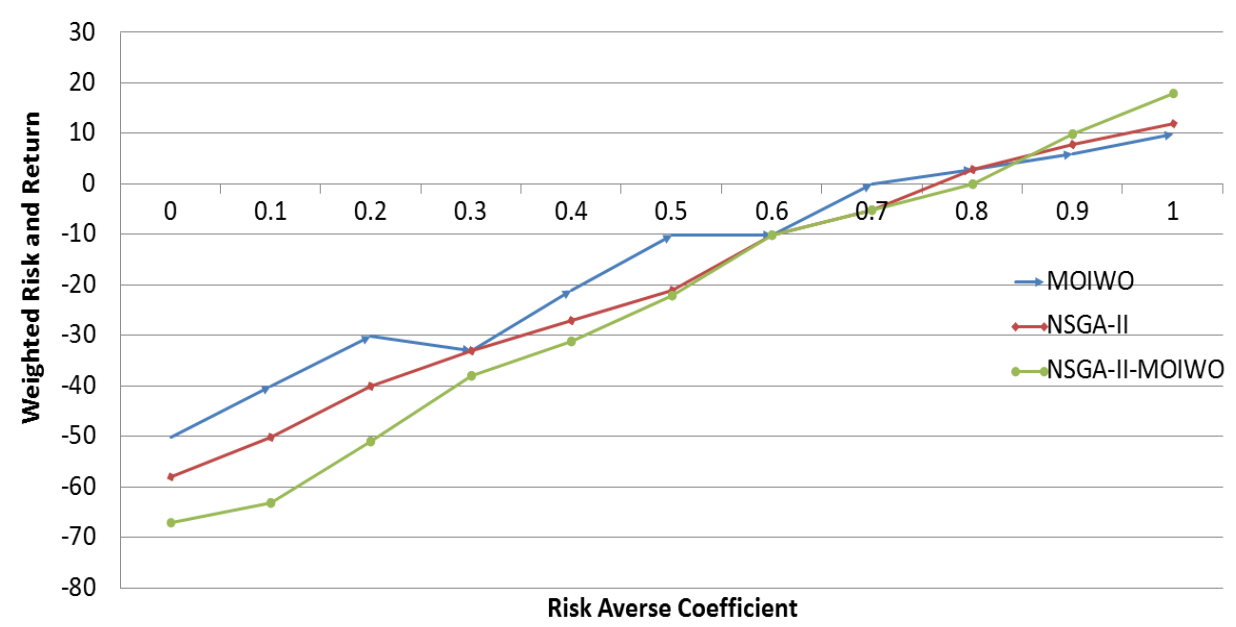

Fig.2 Objective Function when $\mathrm{K}=10$

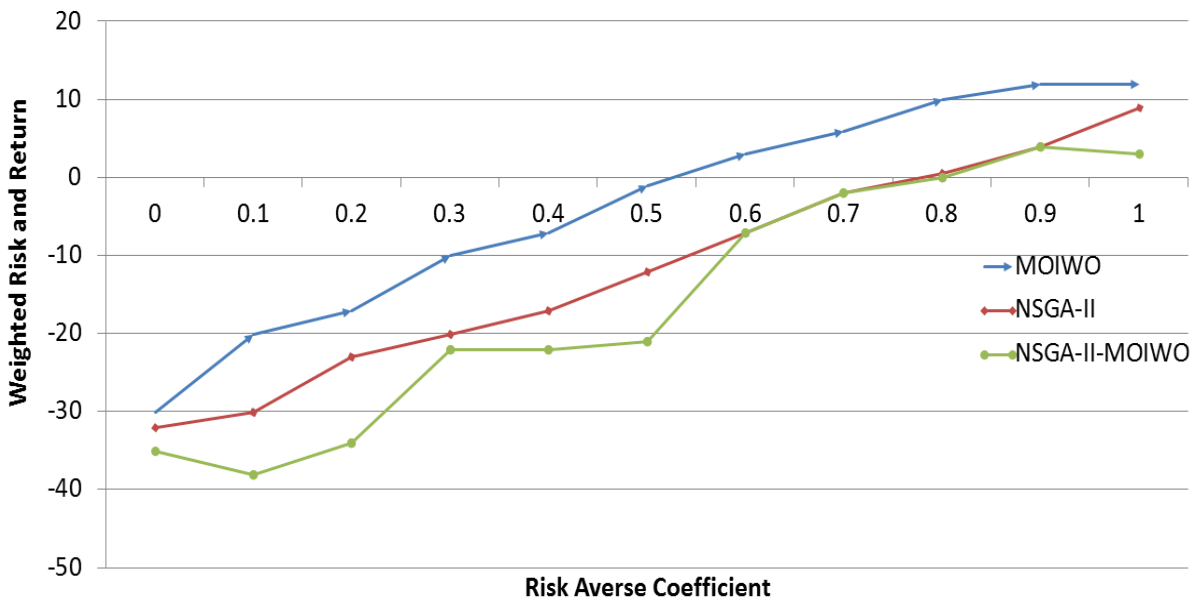

Fig.3. Objective Function when $\mathrm{K}=50$

One way of checking the quality of the algorithm is by determining how quickly they are able to reach towards the desired solution. Based on the results obtained for varying values of $\mathrm{k}$, the proposed algorithm is used to take a comparative note on MOIWO and NSGA algorithms for repetitions of different values. Accordingly, when we assume the replication number to be 100, the weighted sum of return as well as risk can be evaluated by setting the risk aversion coefficient to be 0.05 for the given algorithms. The obtained results in the figures Fig.2 and Fig. 3 indicate that at a minimum level of iteration 50, the proposed algorithm converges while the basic algorithm of MOIWO and NSGA-III converges at values greater than 60 . This indicates that the proposed algorithm tends to converge at a quicker rate when compared to the other algorithms. 
Journal of Information Technology and Digital World (2020)

Vol.02/ No. 02

Pages: $116-122$

https://www.irojournals.com/itdw/

DOI: https://doi.org/10.36548/jitdw.2020.2.005

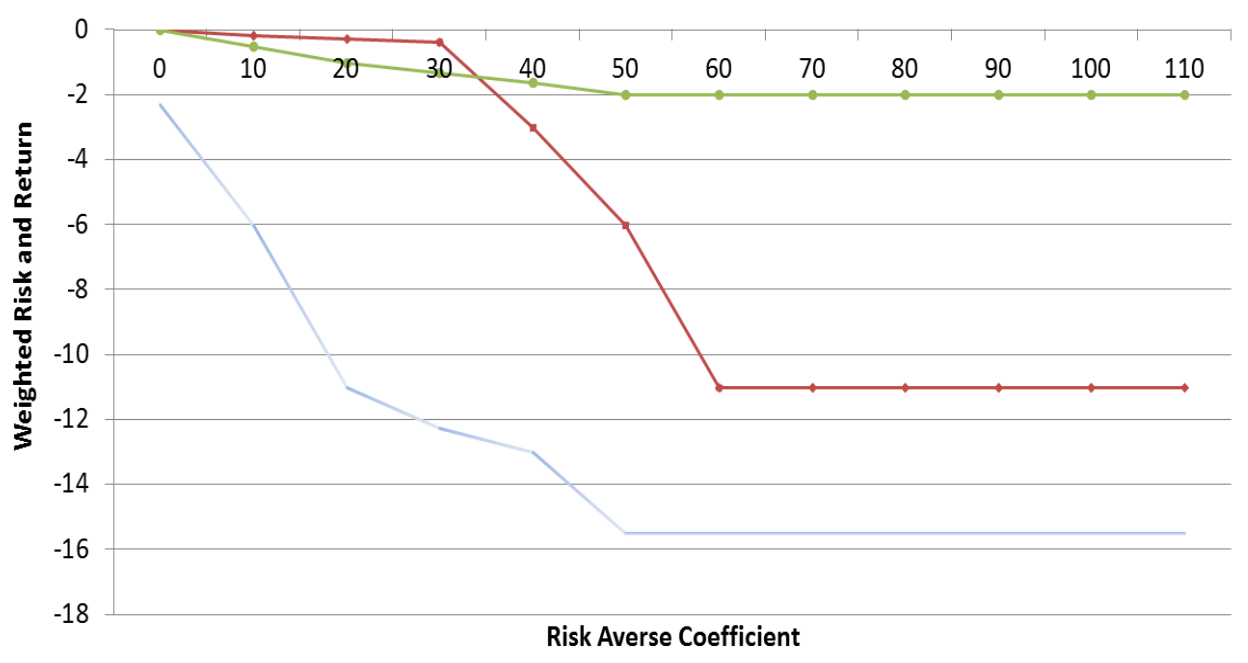

Fig. 4 Convergence Analysis

\section{Conclusion}

In this paper, a solution to the EPPS problem has been analyzed by formulating a novel approach of a hybrid algorithm namely NSGA-II-MOIWO. This algorithm is a combination of the positive features of the MOIWO algorithm and NSGA-II algorithm. The algorithm is focused on reducing the risk of EPPS problem by taking into consideration kurtosis, skewness and variance. Since the data gathered is in the raw format, it is converted to usable form using fuzzy parameters and the obtained data is fed into a decision making procedure that runs on big data. A detailed analysis is made on the return and risk on investment for social media E-portfolios and it is identified that the proposed NSGA-II-MOIWO algorithm gives a better prediction to select the best portfolio. The observed results were analyzed and it is determined that this methodology outperforms other algorithm in terms of run time value, GAP, fitness evaluation and fitness diversification. The crucial advancement of the carried out research work is that it is possible to build the best E-project portfolio with minimal amount of information. In the future, this algorithm can be further enhanced by using different methodologies with less risk measure. Similarly, the use of uncertainty techniques will play a crucial role in further investigating the behavior of the system for varying values of $\mathrm{K}$ and to further improve the proposed algorithm.

\section{References}

[1] Menon, V. G., \& Khosravi, M. R. (2019). Preventing hijacked research papers in fake (rogue) journals through social media and databases. Library Hi Tech News.

[2] P. N. Kolm, R. Tütüncü, and F. J. Fabozzi, "60 Years of portfolio optimization: Practical challenges and current trends," European Journal of Operational Research, vol. 234, no. 2, pp. 356-371, 2014. 
Journal of Information Technology and Digital World (2020)

Vol.02/ No. 02

Pages: $116-122$

https://www.irojournals.com/itdw/

DOI: https://doi.org/10.36548/jitdw.2020.2.005

[3] L. L. Macedo, P. Godinho, and M. J. Alves, "Mean-semivariance portfolio optimization with multi-objective evolutionary algorithms and technical analysis rules," Expert Systems with Applications, vol. 79, pp. 33-43, 2017.

[4] H. Babazadeh and A. Esfahanipour, "A novel multi period mean- VaR portfolio optimization model considering practical constraints and transaction cost," Journal of Computational and Applied Mathematics, vol. 361, pp. 313-342, 2019.

[5] X. Huang, "Mean-semivariance models for fuzzy portfolio selection," Journal of computational and applied mathematics, vol. 217, no. 1, pp. 1-8, 2008.

[6] M. Tavana, M. Keramatpour, F. J. Santos-Arteaga, and E. Ghorbaniane, "A fuzzy hybrid project portfolio selection method using data envelopment analysis, TOPSIS and integer programming," Expert Systems with Applications, vol. 42, no. 22, pp. 8432-8444, 2015.

[7] F. Pérez, T. Gómez, R. Caballero, and V. Liern, "Project portfolio selection and planning with fuzzy constraints," Technological Forecasting and Social Change, vol. 131, pp. 117-129, 2018.

[8] R. Saborido, A. B. Ruiz, J. D. Bermúdez, E. Vercher, and M. Luque, "Evolutionary multiobjective optimization algorithms for fuzzy portfolio selection," Applied Soft Computing, vol. 39, pp. 48-63, 2016.

[9] [18] K. Liagkouras and K. Metaxiotis, "Multi-period mean-variance fuzzy portfolio optimization model with transaction costs," Engineering Applications of Artificial Intelligence, vol. 67, pp. 260- 269, 2018.

[10] N. A. Ghani, S. Hamid, I. A. T. Hashem and E. Ahmed, "Social media big data analytics: A survey," Computers in Human Behavior, vol. 101, pp. 417-428, 2019.

[11] R. De Neufville, K. Smet, M. A. Cardin and M. Ranjbar-Bourani, "Engineering Options Analysis (EOA): Applications," In Decision Making under Deep Uncertainty, Springer, Cham, 2019.

[12] Sathesh, A. Enhanced Soft Computing Approaches For Intrusion Detection Schemes In Social Media Networks. Journal Of Soft Computing Paradigm (Jscp), 1(02), 69-79, 2019.

\section{Authors Biography}

The author Dr. A. Pasumponpandian, Professor,has completed his UG and PG degree from the reputed colleges and works as Professor,in ComputerScience Engineering, KGISL Institute of Technology, Coimbatore, India. His areas of research includes Social Networks, Wireless Networks, Internet of Things, Computer Networks, Mobile Communication, Robotics and Electrical Infrastructure, Mobile APIs, Data Analysis and Visualization. 